\title{
The Chinese version of the Coronary Artery Disease Education Questionnaire-II (CADEQ-II): translation and validation
}

This article was published in the following Dove Press journal:

Patient Preference and Adherence

\author{
Zi Chen' \\ Jing Geng ${ }^{2}$ \\ Mian Wang ${ }^{3}$ \\ Liu $\mathrm{Hu}^{4}$ \\ Gabriela Lima de Melo \\ Ghisi ${ }^{5}$ \\ Huidan Yu' \\ 'School of Health Sciences, Wuhan \\ University, Wuhan, Hubei, 43007I, \\ China; ${ }^{2}$ Department of Cardiovascular \\ Medicine, Renmin Hospital of Wuhan \\ University, Wuhan, Hubei, 430060 , \\ China; Infrastructure Management \\ Department, Renmin Hospital of \\ Wuhan University, Wuhan, Hubei, \\ 430060, China; ${ }^{4}$ Department of \\ Nursing, Wuhan Asian Heart Hospital, \\ Wuhan, Hubei, 430022, China; \\ ${ }^{5}$ Cardiovascular Prevention and \\ Rehabilitation Program, Toronto \\ Rehabilitation Institute (TRI), \\ University Health Network (UHN), \\ University of Toronto, Toronto, \\ ON, Canada
}

Objectives: It is necessary to assess disease-related knowledge in patients with coronary artery disease (CAD) for tailored patient education; however there is a lack of a well-validated measurement in China. The objective of this study was to translate and validate a Chinese version of the Coronary Artery Disease Education Questionnaire-II (CADEQ-II).

Methods: The Chinese version of CADEQ-II was translated and culturally adapted. Then, it was tested for psychometric properties through a convenient sampling. Content validity was examined based on a panel of five experts. The item difficulty index and item discrimination index were calculated to assess the item difficulty and item discrimination. Internal consistency reliability was measured with the Cronbach's alpha coefficient. Criterion-related validity was established through comparing scores in patients with different education levels. Construct validity was assessed through confirmatory factor analysis (CFA).

Results: The Chinese version of the CADEQ-II was finalized after deleting three items and modifying two items from the original version. Three hundred and sixteen participants completed the whole questionnaire. Content validity index of the whole questionnaire was 0.87 . The Cronbach's alpha coefficient of the overall questionnaire was 0.907 . The significant difference of the knowledge scores among patients with different education levels supported criterion-related validity. CFA confirmed the proposed four-factorial structure of the questionnaire.

Conclusion: The Chinese version of CADEQ-II had an acceptable reliability and validity among Chinese patients with CAD. It could be used to develop individualized health education for Chinese patients with CAD. Also, it could serve as a suitable outcome measurement to evaluate the effectiveness of education interventions related to CAD.

Keywords: coronary artery disease, education, validation

\section{Introduction}

As global burden of diseases shifted, cardiovascular disease (CVD) became a major cause of mortality and disability worldwide. ${ }^{1}$ It is estimated that CVD would cause $\sim 25$ million deaths by 2020 . $^{2}$ In China, the prevalence of CVD is on the rise with the development of economy and the change in lifestyle. ${ }^{3}$ Among all the CVD, coronary artery disease (CAD) is a leading cause of morbidity and mortality in China. ${ }^{4}$ According to the statistics, the mortality rate of CAD in China was 107.5/100,000 and 105.37/100,000 in the city and countryside, respectively, in $2014 .^{4}$

Individuals with CAD often suffer from chronic conditions in a long term, which lead to a dire need of adequate and correct disease-related knowledge for disease management. 5 ,6 Disease-related knowledge refers to the basic understanding of the disease and relevant information about self-management, such as exercise, risk factor
Correspondence: Huidan Yu School of Health Sciences, Wuhan University, No. II 5 Donghu Road, Wuchang District, Wuhan, Hubei, 43007I, China

Tel +86 I 3006330898

Fax +86 2768758747

Email yuhuidan32@I26.com
Patient Preference and Adherence 20I8:12 I587-1596

1587

Dovepress f $y$ in 0

http://dx.doi.org/|0.2147/PPA.S176639 (c) (1) (-) 2018 Chen et al. This work is published and licensed by Dove Medical Press Limited. The full terms of this license are available at https://www.dovepress.com/terms.php cc) and incorporate the Creative Commons Attribution - Non Commercial (unported, v3.0) License (http://creativecommons.org/licenses/by-nd/3.0/). By accessing the work you hereby accept the Terms. Non-commercial uses of the work are permitted without any further permission from Dove Medical Press Limited, provided the work is properly attributed. For permission for commercial use of this work, please see paragraphs 4.2 and 5 of our Terms (https://www.dovepress.com/terms.php). 
management, and dietary. ${ }^{7}$ Previous studies have proven that adequate disease-related knowledge can enhance patients' awareness of existing risk factors and improve their adherence to healthy lifestyle, which may lead to better cardiovascular health. ${ }^{8,9}$

Health education is a cost-effective approach to improve disease-related knowledge of patients with CAD. ${ }^{10}$ It serves as a significant part of disease management and secondary prevention, which can help patients understand the therapies and comply with the recommended health behaviors. ${ }^{11,12}$ Findings from recent studies presented the benefits of patient education in improving self-management abilities and quality of life while reducing healthcare costs. ${ }^{12,13}$

Disease-related knowledge is a primary and sensitive outcome of health education programs. By assessing diseaserelated knowledge of patients with $\mathrm{CAD}$, healthcare professionals can develop tailored health education and evaluate the effectiveness of the intervention. ${ }^{14}$ Therefore, it is essential to have a suitable tool to measure disease-related knowledge for patients with CAD. However, there lacks a reliable and valid instrument for assessing disease-related knowledge among individuals living with CAD in China. ${ }^{15,16}$ Currently, the commonly used instrument was a questionnaire developed by Meilian and Tao. ${ }^{17}$ However, such a 54 -item questionnaire has not been rigorously validated yet, also it does not include contents regarding the psychological factors related to CAD, which fails to comprehensively reflect patients' knowledge regarding CAD. ${ }^{16,18,19}$

The Coronary Artery Disease Education Questionnaire-II (CADEQ-II), developed by Ghisi et $\mathrm{al}^{20}$ in 2015, is used to measure disease-related knowledge related to CAD (Figure S1). It contains 31 items involving five domains including medical condition, risk factors, exercise, nutrition, and psychological risks. Each item has four response options indicating "complete knowledge" (3 points), "incomplete knowledge" (1 point), "wrong knowledge" (0 point), and "lack of knowledge" (0 point). The total score of CADEQ-II ranges from 0 to 93 , with a higher score suggesting better CAD-related knowledge.

CADEQ-II is the second version of the CADEQ. ${ }^{20}$ This instrument is developed based on a series of empirical researches conducted by Ghisi et al. ${ }^{21-23}$ The scope of CADEQ-II covers almost all components of the cardiac care, including the psychosocial risks of CAD. ${ }^{20}$ Unlike other similar tools using yes (true) or no (false) options, CADEQ-II consists of items with multiple choices, which can better reflect patients' awareness of the disease. ${ }^{14}$ Also, it applies the "I do not know" option to avoid guessing. ${ }^{24}$ As a newly developed measurement, CADEQ-II has been validated in
Canadian patients with CAD and has shown good reliability and validity. ${ }^{20}$ The Cronbach's alpha was 0.91 for the whole questionnaire and was ranged from 0.65 to 0.77 for each domain. To date, CADEQ-II has been translated into many languages other than Chinese ${ }^{25}$ and no evidence about the psychometric properties of CADEQ-II in diverse cultural backgrounds has been published.

This study aimed to translate the CADEQ-II into Chinese and test its psychometric properties in Chinese patients with CAD in clinical settings, which would help health professionals to evaluate disease-related knowledge of Chinese patients with CAD.

\section{Methods \\ Design and procedure}

This study was conducted with two phases. In the first phase, forward-translation, back-translation, and cultural adaptation were conducted to finalize the draft Chinese version of CADEQ-II for further psychometric test. In the second phase, the psychometric properties of CADEQ-II were tested using a cross-sectional survey. The study was approved by the Institutional Review Board of Wuhan University.

\section{Phase I: forward-translation, back- translation, and cultural adaptation}

\section{Step I: forward-translation}

After getting the permission of the original author, two translators who are proficient in both English and Chinese have independently translated the CADEQ-II from English into Chinese as per Guillemin et al' ${ }^{26}$ recommendation. One of the translators has a doctorate in cardiovascular nursing and is familiar with the CAD-related terms. The other translator is a postgraduate student majored in nursing. After obtaining two Chinese versions, a professional translator and the first author checked the translations and synthesized them into one. Discussions were held among the translators to achieve consensus when controversy in statements and ambiguity in wording had occurred.

\section{Step 2: back-translation}

A bilingual professor without the background in CVD and nursing was invited to back translate the synthesized Chinese version of the CADEQ-II into English. This professor is a Chinese American who has lived in the USA for more than a decade. Then, the back-translated version and original English version were reviewed by the professional translator to ensure the equivalence and consistency. Further revision 
was made to solve the disparities and formed a semifinished Chinese version.

\section{Step 3: cultural adaptation (an expert panel and pilot testing)}

A panel of five experts (including a cardiologist, a nursing professor, and three senior nurses engaged in cardiac caring) reviewed the items of the Chinese version and provided suggestions to improve the accuracy, clarity, suitability, and significance of each item. The content validity was evaluated by this panel.

Then, the Chinese version of CADEQ-II was preliminarily tested in 40 Chinese patients with CAD to evaluate its readability and clarity. The sample size of the pilot test was determined according to the recommendation from Beaton et al. ${ }^{27}$ After completing the questionnaire, participants were interviewed for the clarity of the instructions and items. The feedback was used for further revision. The draft Chinese version of CADEQ-II was finalized after the above steps.

\section{Phase II: the psychometric testing of the Chinese version of the CADEQ-II}

The draft Chinese version was administered to a convenience sample of Chinese patients hospitalized with CAD. The aim was to establish the psychometric properties of this translated questionnaire.

\section{Participants}

Participants were recruited from three large tertiary general hospitals in Wuhan, China. The inclusion criteria were as follows: 1) patients had confirmed the diagnoses of CAD based on the medical record; 2) patients being able to read and understand Mandarin; and 3) patients aged older than 18 years. The exclusion criteria were as follows: 1) patients with any cognitive disorders or mental illness, which may jeopardize the understanding and answering the questionnaire and 2) patients with severe dysfunction of main organs or having serious medical complications.

All patients hospitalized with CAD who fulfilled the inclusion criteria received the written description about this research. Then, participants were asked to complete the demographic questionnaire and the Chinese version of CADEQ-II after they agreed to participate and signed the written informed consent. In this study, the sample size for psychometric analysis was determined based on the recommendation that 10 cases for each item and at least 100 cases for the total instrument. ${ }^{28}$

\section{Statistical analysis}

The demographic data and knowledge scores were described using descriptive statistics. Continuous variables were presented as mean values and standard deviation (SD), while categorical/nominal variables were presented as frequencies and percentages. Before data analysis, all relevant data were tested for normality distribution by checking skewness and kurtosis values, with a $P$-value of $<0.05$ considered a violation of the normality assumption. ${ }^{29}$

Content validity was evaluated by the expert panel, which comprised a cardiologist, a nursing professor, and three senior cardiology nurses. Experts were asked to rate each item on a 4-point Likert scale ( $1=$ completely uncorrelated to $4=$ strongly correlated) based on the content applicability and the clarity of the phrasing. ${ }^{30}$ Content validity was assessed by the content validity index (CVI). ${ }^{30,31} \mathrm{CVI}$ of each item (I-CVI) was calculated as the number of the score $>3$ divided by the total number of the experts. The value $>0.7$ was regarded as acceptable. ${ }^{32}$ The CVI of the whole questionnaire was estimated by calculating the average content validity indices of all the items..$^{33}$ Items with unacceptable CVI value were reevaluated and revised.

The item analysis was conducted to do the item selection and assess item difficulty and discrimination. The item-total correlation and the Cronbach's alpha coefficient were calculated to identify the problematic items of the questionnaire. Item difficulty referred to how frequently respondents responding to each item of a measurement correctly. ${ }^{34}$ In this study, the item difficulty index was applied to assess the difficulty of this questionnaire. The index for each item was calculated by the ratio of the number of correct responses to the total number of responses, the higher value indicating the lower difficulty of this item. ${ }^{34}$ If the value of an item was $<20 \%$ or $>80 \%$, this item should be considered to remove. ${ }^{34,35}$ Item discrimination indicated whether the questionnaire was capable to differentiate the participants' knowledge level according to the score they achieved ${ }^{34}$ In this study, item discrimination index was calculated by the formula: $P_{\mathrm{U}}-P_{\mathrm{L}}$, where $P_{\mathrm{U}}$ was the percentage of respondents who obtained a correct answer in the top $27 \%$ scorers and $P_{\mathrm{L}}$ was the percentage of those who provided a correct response in the upper $27 \%$ scores ${ }^{34} \mathrm{~A}$ value of $\geq 0.4$ was regarded as high. ${ }^{36}$

The internal consistency reliability was measured with Cronbach's alpha coefficients. ${ }^{28}$ The value $>0.6$ was generally considered to be acceptable. ${ }^{37}$ Since previous studies have shown that education is closely related to patients' disease-related knowledge,,$^{20,38-40}$ the criterion validity in 
this study was calculated, in accordance with the original validation study, by comparing the total scores of patients with different educational levels.

The construct validity was examined through confirmatory factor analysis (CFA). CFA was a modeling technique to confirm whether a proposed factorial structure could manifest the correlation or covariance of observable variables. ${ }^{41}$ The factorial structure of the original English version of CADEQ-II was established through exploratory factor analysis (EFA). ${ }^{20}$ EFA revealed a four-factor structure, which explained $62 \%$ of the total variance. ${ }^{20}$ Therefore, in this study, CFA was conducted to test this four-factor model. In order to prevent multivariate nonnormal distribution, robust maximum likelihood (MLR) estimation was used to perform CFA, ${ }^{42}$ The following indices, including chi square by $d f$ ratio $\left(\chi^{2} / d f\right)$, goodnessof-fit index (GFI), comparative fit index (CFI), root mean square error of approximation (RMSEA), and standardized root mean square residual (SRMR), were used to perform the goodness-of-fit assessment. ${ }^{43}$ In this study, $1 \leq \chi^{2} / d f \leq 3$, GFI $>0.90$, CFI $>0.90$, RMSEA $\leq 0.08$, and $\mathrm{SRMR}<0.08$ were considered to be acceptable. ${ }^{44,45}$

The scores of patients with different demographic characteristics were also analyzed. The SPSS 22.0 (IBM Corporation, Armonk, NY, USA) and Mplus v.7.0 (Muthén and Muthén, Los Angeles, CA, USA) were used for the statistical analysis. An alpha level of $\leq 0.05$ was considered to be statisticaly significant (two-tailed test).

\section{Results}

\section{Demographic characteristics}

A total of 330 eligible subjects were recruited for the psychometric analysis. Of these 330 participants, 10 patients refused to participate in this research and four patients did not complete the whole questionnaire. The reason for those who refused to participate included the lack of time or interest. Finally, a total of 316 patients completed the questionnaire. The age of subjects ranged from 21 to 86 years, with a mean age of $60.84 \pm 11.75$ years. Over half of the participants (179) were aged $>60$ years. The demographic characteristics of participants are listed in Table 1.

\section{Results of the cultural adaptation}

Through discussion of the expert panel, two items were modified and one item was deleted. The second option "frozen dinners" of item 4 in the nutrition domain was modified as "quick-frozen food". The statement "blood pressure" of item 1 in the risk factors' domain was revised as "hypertension".
Item 4 of the exercise domain was deleted because most Chinese people were not familiar with the wind chill.

Forty patients hospitalized with CAD participated in the pilot test. The average time of completion was 28.2 \pm 5.7 minutes. The feedback indicated that there was no ambiguous or unclear item in this translated version. After cultural adaptation, a draft Chinese version of the CADEQ-II, with 30 items retained, was prepared for the next formal psychometric test.

As for the content validity, I-CVIs ranged from 0.80 to 1.00 , all $>0.70$. CVI for the whole questionnaire was 0.87 . The results indicated an adequate content validity of the questionnaire.

\section{Item analysis}

Item exclusion

Item 5 in the medical condition domain "The best resources available to help someone understand his/her medications are ( )" was omitted due to the unacceptable item-total correlation coefficient ( $r=-0.074, P=0.651)$. Item 4 in the risk factors domain "The first step toward controlling a risk factor (such as blood pressure or cholesterol) is ( )" was deleted due to its negative impact on the Cronbach's alpha coefficient of the risk factors domain (substantially increased to 0.687 when it was deleted).

\section{Item difficulty and item discrimination}

Item difficulty index and item discrimination index are shown in Table 2. The mean value of item difficulty index was $0.54 \pm 0.14$, which reflected a moderate level of difficulty. ${ }^{34}$ Item difficulty indices of all items ranged from 0.20 to 0.74 . The mean value of item discrimination index was $0.48 \pm 0.09$. All discrimination indices were $>0.30$, with $86 \%$ of which were $>0.4$, indicating a good item discrimination of the Chinese version of CADEQ-II.

Finally, three items were deleted and two items were modified from the original version. A total of 28 items were included in the final Chinese version of CADEQ-II (Figure S2), with six items in the medical domain, four items in the risk factor domain, six items in the exercise domain, seven items in the nutrition domain, and seven items in the psychological risk domain. The total score of the Chinese version of CADEQ-II ranged from 0 to 84 .

\section{Reliability}

The Cronbach's alpha coefficients were 0.907 for the overall questionnaire, 0.692 for the medication condition domain, 0.687 for the risk factors' domain, 0.714 for the exercise 
Table I Demographic characteristics of participants

\begin{tabular}{|c|c|c|c|c|}
\hline Variable & $\mathbf{N}(\%)$ & Scores (mean $\pm \mathbf{S D})$ & T/F & $P$-value \\
\hline \multicolumn{5}{|l|}{ Gender } \\
\hline Male & $215(68)$ & $46.84 \pm 18.56$ & 1.465 & 0.414 \\
\hline Female & $101(32)$ & $43.50 \pm 19.75$ & & \\
\hline Marital status & & & 1.837 & 0.161 \\
\hline Married & $300(94.9)$ & $45.90 \pm 18.81$ & & \\
\hline Single & $6(1.9)$ & $53.83 \pm 20.01$ & & \\
\hline Divorced/widowed & $10(3.2)$ & $36.20 \pm 20.80$ & & \\
\hline Employment & & & 1.749 & 0.176 \\
\hline Retirement & $184(58.2)$ & $45.46 \pm 19.18$ & & \\
\hline Employment & $98(31.0)$ & $48.11 \pm \mid 7.91$ & & \\
\hline Unemployment & $34(10.8)$ & $41.26 \pm 19.75$ & & \\
\hline Living area & & & 14.22 & $<0.001$ \\
\hline City & $209(66.2)$ & $49.32 \pm 17.53$ & & \\
\hline Suburb & $21(6.6)$ & $46.43 \pm 16.97$ & & \\
\hline Countryside & $86(27.2)$ & $36.90 \pm 19.96$ & & \\
\hline Insurance & & & 28.372 & $<0.001$ \\
\hline Health insurance for urban citizens & $204(64.5)$ & $50.76 \pm 16.54$ & & \\
\hline Rural cooperative health insurance & $90(28.5)$ & $34.11 \pm 19.24$ & & \\
\hline Others & $22(7.0)$ & $46.82 \pm \mid 8.41$ & & \\
\hline Education background & & & 42.064 & $<0.001$ \\
\hline Primary school and below & $63(19.9)$ & $29.90 \pm 19.77$ & & \\
\hline Middle school & 94 (29.7) & $41.29 \pm 15.93$ & & \\
\hline High school & $87(27.6)$ & $51.24 \pm 14.78$ & & \\
\hline Bachelor degree and above & $72(22.8)$ & $58.78 \pm 13.95$ & & \\
\hline Comorbidity & & & 7.413 & $<0.001$ \\
\hline No & $109(34.5)$ & $40.65 \pm 19.40$ & & \\
\hline With one comorbidity & $107(33.8)$ & $44.63 \pm 18.54$ & & \\
\hline With two comorbidities & $66(20.9)$ & $52.23 \pm 16.61$ & & \\
\hline With three comorbidities & $34(10.8)$ & $52.79 \pm|7.7|$ & & \\
\hline History of coronary artery disease & & & 1,029 & 0.359 \\
\hline$\leq 3$ months & $174(55.1)$ & $44.55 \pm 19.26$ & & \\
\hline 3 months to I year & $14(4.4)$ & $43.79 \pm 18.30$ & & \\
\hline$\geq \mathrm{I}$ year & $128(40.5)$ & $47.58 \pm 18.56$ & & \\
\hline
\end{tabular}

Note: a Comorbidity, such as hypertension, diabetes, and hyperlipidemia.

domain, 0.705 for the nutrition domain, and 0.701 for the psychological risk domain (Table 3 ). The internal consistency reliability for the whole questionnaire and each domain was acceptable.

\section{Criterion-related validity}

The result showed that patients with different educational levels had different knowledge scores $(F=42.064, P<0.001)$. Pairwise comparison using the least significant difference method found that the patients with higher educational background scored higher $(P<0.001)$, which indicated an acceptable criterion-related validity of the questionnaire.

\section{Construct validity}

The present study performed CFA to test a proposed four-factor model established in Ghisi et al' ${ }^{20}$ study.
Results showed that the proposed model fitted data well $\left(\chi^{2} / d f=1.651 ;\right.$ RMSEA $=0.045 ;$ CFI $=0.922 ;$ GFI $=0.914$; SRMR $=0.049)$. All items had significant parameters on the designated factor $(P<0.001)$. Factor loading coefficients ranged from 0.470 to 0.663 (Table 4 ), which were above the acceptable level. ${ }^{46}$ The results of CFA provided evidence that the Chinese version of CADEQ-II with a four-factorial structure had sound construct validity.

\section{Patient knowledge}

The mean total score of the Chinese version of the CADEQ-II was $45.74 \pm 18.94$ (the full score is 84 ). Patients scored highest in the domain of medical condition and exercise $(10.86 \pm 4.72,10.76 \pm 4.90)$ but lowest in the domain of risk factors $(6.82 \pm 3.55)$. As for individual items, the first and 
Table 2 Item difficulty and item discrimination

\begin{tabular}{|c|c|c|c|}
\hline Domains & $\begin{array}{l}\text { Questions } \\
\text { (items) }\end{array}$ & $\begin{array}{l}\text { The item } \\
\text { difficulty } \\
\text { index }(P)\end{array}$ & $\begin{array}{l}\text { The item } \\
\text { discrimination } \\
\text { index }(D)\end{array}$ \\
\hline \multirow[t]{6}{*}{ Medical condition } & 1 & 0.65 & 0.51 \\
\hline & 2 & 0.68 & 0.37 \\
\hline & 3 & 0.72 & 0.34 \\
\hline & 4 & 0.48 & 0.32 \\
\hline & 5 & 0.68 & 0.55 \\
\hline & 6 & 0.41 & 0.51 \\
\hline \multirow[t]{4}{*}{ Risk factors } & 1 & 0.53 & 0.59 \\
\hline & 2 & 0.59 & 0.65 \\
\hline & 3 & 0.70 & 0.43 \\
\hline & 4 & 0.45 & 0.54 \\
\hline \multirow[t]{6}{*}{ Exercise } & 1 & 0.41 & 0.55 \\
\hline & 2 & 0.67 & 0.56 \\
\hline & 3 & 0.5 & 0.48 \\
\hline & 4 & 0.63 & 0.43 \\
\hline & 5 & 0.74 & 0.40 \\
\hline & 6 & 0.64 & 0.50 \\
\hline \multirow[t]{7}{*}{ Nutrition } & 1 & 0.23 & 0.44 \\
\hline & 2 & 0.20 & 0.30 \\
\hline & 3 & 0.58 & 0.55 \\
\hline & 4 & 0.64 & 0.45 \\
\hline & 5 & 0.62 & 0.49 \\
\hline & 6 & 0.47 & 0.41 \\
\hline & 7 & 0.36 & 0.53 \\
\hline \multirow[t]{5}{*}{ Psychological risk } & 1 & 0.59 & 0.46 \\
\hline & 2 & 0.50 & 0.49 \\
\hline & 3 & 0.59 & 0.59 \\
\hline & 4 & 0.48 & 0.67 \\
\hline & 5 & 0.51 & 0.44 \\
\hline
\end{tabular}

second items in the nutrition domain got the lowest scores $(0.68 \pm 1.12,0.59 \pm 1.03)$. Details are presented in Table 3.

Scores of patients with different demographic characteristics were examined to explore the influencing factors of their knowledge level. The result showed that the living areas ( $F=14.220, P<0.001)$, insurance type $(F=28.372, P<0.001)$, education level $(F=42.064, P<0.001)$, and comorbidities $(F=7.413, P<0.001)$ significantly impacted the patients' disease-related knowledge. Pairwise comparison indicated that patients who live in cities and suburbs $(P<0.001$, $P=0.032$ ), hold the health insurance for urban citizens $(P<0.001)$, have higher education level $(P<0.001)$ and have two $(P<0.001)$ or more $(P=0.001)$ comorbidities achieved higher knowledge scores than their counterparts. Although statistically significant $(r=-0.015, P=0.010$ ), the correlation between knowledge scores and the age was feeble. Details are listed in Table 1.

\section{Discussion}

The aim of this study was to translate and validate the Chinese version of the CADEQ-II among patients hospitalized with
CAD in China. The Chinese version of the CADEQ-II was formed after deleting three items and modifying two items from the original version. Psychometric analysis showed that this 28-item questionnaire had acceptable reliability and validity. Therefore, it could be considered as an ideal measurement for assessing disease-related knowledge of Chinese patients with CAD.

Item difficulty and item discrimination were the parts of the item analysis in the context of the classical test theory. ${ }^{47}$ Item difficulty, also called item severity, referred to the ratio of those who obtain correct responses. ${ }^{34}$ For an instrument, especially the knowledge measurement, very difficult or very easy items were not sufficient to distinguish well or poorly performed respondents. Therefore, the level of difficulty for most items should be in a moderate level. ${ }^{34}$ As shown in Table 2, the overall item difficulty of this questionnaire was in a moderate level. Although two items in the nutrition domain were relatively difficult, the value of the item difficulty index was still acceptable. Also, nutrition knowledge measured by these two items was the essential information of CAD management. The low score of these two items revealed an insufficiency of nutrition knowledge in Chinese patients hospitalized with CAD as well as a deficiency of current health education, which was also discussed in previous studies. ${ }^{48,49}$ Item discrimination reflected the discriminatory effectiveness of a particular item to distinguish respondents who were knowledgeable about the measure and those who were not. ${ }^{34}$ Results showed that the item discrimination of this knowledge questionnaire was adequate, which indicated that this measurement could effectively distinguish respondents who were knowledgeable related to CAD with those who were not. To date, no published research reported item difficulty and item discrimination of this questionnaire. The analysis of item difficulty and discrimination in present study filled this gap.

The internal consistency reliability manifested the internal correlation between items and dimensions. ${ }^{50}$ The overall Cronbach's alpha coefficient of the questionnaire was highly acceptable, and the Cronbach's alpha coefficient for each domain also met the acceptable level, which supported the acceptable internal consistency reliability of this translated version.

Since previous studies have demonstrated that patients who received higher education had more knowledge about disease, ${ }^{20,38-40}$ the education level was served as the criterion to examine the criterion-related validity of this questionnaire, which is the same approach used in the original validation study. ${ }^{20}$ The result showed that patients with higher 
Table 3 The score of CADEQ-II and Cronbach's alpha coefficients

\begin{tabular}{|c|c|c|c|c|c|}
\hline $\begin{array}{l}\text { Domain } \\
\text { (maximum score) }\end{array}$ & Item & $\begin{array}{l}\text { Score } \\
(\text { mean } \pm \text { SD) }\end{array}$ & $\begin{array}{l}\text { Mean score } \\
\text { per domain } \\
(\text { mean } \pm S D)\end{array}$ & $\begin{array}{l}\text { Item total } \\
\text { score } \\
\text { correlations }\end{array}$ & $\begin{array}{l}\text { Cronbach's } \\
\text { alpha coefficient } \\
\text { per domain }\end{array}$ \\
\hline \multirow[t]{6}{*}{ Medical condition (18) } & I & $1.94 \pm 1.32$ & $10.86 \pm 4.72$ & $0.529 * *$ & 0.692 \\
\hline & 2 & $2.05 \pm 1.23$ & & $0.499 * *$ & \\
\hline & 3 & $2.17 \pm 1.10$ & & $0.494 * *$ & \\
\hline & 4 & $1.45 \pm 1.25$ & & $0.359 * *$ & \\
\hline & 5 & $2.04 \pm 1.33$ & & $0.578 * *$ & \\
\hline & 6 & $1.22 \pm 1.27$ & & $0.529 * *$ & \\
\hline \multirow[t]{4}{*}{ Risk factors (I2) } & I & $1.60 \pm 1.26$ & $6.82 \pm 3.55$ & $0.63 I^{* *}$ & 0.687 \\
\hline & 2 & $1.78 \pm 1.31$ & & $0.668 * *$ & \\
\hline & 3 & $2.10 \pm 1.13$ & & $0.513^{* *}$ & \\
\hline & 4 & $1.34 \pm 1.23$ & & $0.585^{* *}$ & \\
\hline \multirow[t]{6}{*}{ Exercise (18) } & I & $1.22 \pm 1.38$ & $10.76 \pm 4.90$ & $0.545^{* *}$ & 0.714 \\
\hline & 2 & $2.01 \pm 1.26$ & & $0.584 * *$ & \\
\hline & 3 & $1.49 \pm 1.29$ & & $0.516 * *$ & \\
\hline & 4 & $1.88 \pm 1.26$ & & $0.478 * *$ & \\
\hline & 5 & $2.23 \pm 1.07$ & & $0.565^{* *}$ & \\
\hline & 6 & $1.93 \pm 1.34$ & & $0.517 * *$ & \\
\hline \multirow[t]{7}{*}{ Nutrition (2I) } & I & $0.68 \pm 1.12$ & $9.28 \pm 5.21$ & $0.564 * *$ & 0.705 \\
\hline & 2 & $0.59 \pm 1.03$ & & $0.439 * *$ & \\
\hline & 3 & $1.74 \pm 1.40$ & & $0.568 * *$ & \\
\hline & 4 & $1.92 \pm 1.31$ & & $0.489 * *$ & \\
\hline & 5 & $1.87 \pm 1.17$ & & $0.596 * *$ & \\
\hline & 6 & $1.40 \pm 1.25$ & & $0.499 * *$ & \\
\hline & 7 & $1.08 \pm 1.36$ & & $0.511 * *$ & \\
\hline \multirow[t]{5}{*}{ Psychological risk (15) } & I & $1.78 \pm 1.24$ & $8.03 \pm 4.50$ & $0.57 \mid * *$ & $0.70 \mathrm{I}$ \\
\hline & 2 & $1.5 \mathrm{I} \pm 1.33$ & & $0.503 * *$ & \\
\hline & 3 & $1.78 \pm 1.34$ & & $0.590 * *$ & \\
\hline & 4 & $1.44 \pm 1.41$ & & $0.673^{* *}$ & \\
\hline & 5 & $1.53 \pm 1.34$ & & $0.488 * *$ & \\
\hline Total & & $45.74 \pm 18.94$ & & 1 & 0.907 \\
\hline
\end{tabular}

Note: $* * p<0.001$.

Abbreviation: CADEQ-II, Artery Disease Education Questionnaire II.

education background were more knowledgeable about CAD, which established a good criterion-related validity of this questionnaire.

In the previous study, the English version of CADEQ-II was shown as a four-factorial structure through EFA, namely the factors of medical conditions, risk factors and exercise, nutrition, and psychological risks. ${ }^{20}$ Therefore, this study performed CFA to confirm this four-factor model. The model fit indices of CFA illustrated that this four-factor model fitted the data well. Factor loadings for all items were significant and exceeded the acceptable criterion. The result of CFA illustrated that the Chinese version of CADEQ-II had satisfactory construct validity when applied into the target sample in the present study.

The overall disease-related knowledge of the participants was at a moderate level $(45.74 \pm 18.94)$, similar to the previous investigations. ${ }^{51,52}$ However, it was lower than the result $(64.2 \pm 18.1)$ of the study conducted in Canada using the
English version of the CADEQ-II (the total score is 93), ${ }^{20}$ indicating the lack of patient education in China. ${ }^{48,49,53,54}$ Whereas the Canadian study did not include patients with low education level, ${ }^{20}$ this may partly explained the higher scores among its participants. Moreover, over half of the participants included in the present study were diagnosed with CAD within 3 months, which might cause the low level of disease-related knowledge among them. Similar to the results of Ghisi et al's ${ }^{20}$ study, patients with CAD had better knowledge regarding the medical condition and exercise but poorer knowledge related to risk factors, which indicated that health care providers should pay more attention to delivering the knowledge about risk factors of CAD to the patients.

In this study, the knowledge scores of patients with different characteristics were also explored. The results, similar to the previous studies, illustrated that patients living in the urban areas, holding the health insurance for citizens, having received higher education levels, and having two 
Table 4 Factor loadings for the four factorial structure

\begin{tabular}{|c|c|c|c|c|c|}
\hline Factor & Items & $\begin{array}{l}\text { Unstandardized } \\
\text { estimate }\end{array}$ & $\begin{array}{l}\text { Standard } \\
\text { error }\end{array}$ & $P$-value & $\begin{array}{l}\text { Standardized } \\
\text { estimate }\end{array}$ \\
\hline \multirow[t]{6}{*}{ Medical condition } & 1 & 1.000 & 0.000 & 999.000 & 0.568 \\
\hline & 2 & 0.920 & 0.122 & $*$ & 0.559 \\
\hline & 3 & 0.788 & 0.099 & $*$ & 0.534 \\
\hline & 4 & 0.848 & 0.095 & $*$ & 0.530 \\
\hline & 5 & 1.127 & 0.123 & $*$ & 0.633 \\
\hline & 6 & 0.872 & 0.119 & $*$ & 0.513 \\
\hline \multirow[t]{10}{*}{ Risk factors and exercise } & 1 & 1.000 & 0.000 & 999.000 & 0.637 \\
\hline & 2 & 1.088 & 0.087 & $*$ & 0.663 \\
\hline & 3 & 0.763 & 0.078 & * & 0.539 \\
\hline & 4 & 0.817 & 0.082 & $*$ & 0.530 \\
\hline & 1 & 0.876 & 0.082 & $*$ & 0.508 \\
\hline & 2 & 0.951 & 0.089 & $*$ & 0.603 \\
\hline & 3 & 0.787 & 0.089 & $*$ & 0.487 \\
\hline & 4 & 0.749 & 0.089 & $*$ & 0.476 \\
\hline & 5 & 0.792 & 0.072 & $*$ & 0.591 \\
\hline & 6 & 0.860 & 0.097 & $*$ & 0.513 \\
\hline \multirow[t]{7}{*}{ Nutrition } & I & 1.000 & 0.000 & 999.000 & 0.545 \\
\hline & 2 & 1.040 & 0.089 & $*$ & 0.584 \\
\hline & 3 & 1.356 & 0.179 & $*$ & 0.605 \\
\hline & 4 & 1.109 & 0.160 & $*$ & 0.525 \\
\hline & 5 & $1.26 \mid$ & 0.139 & $*$ & 0.643 \\
\hline & 6 & 1.034 & 0.137 & $*$ & 0.509 \\
\hline & 7 & 1.054 & 0.137 & $*$ & 0.478 \\
\hline \multirow[t]{5}{*}{ Psychosocial risks } & 1 & 1.000 & 0.000 & 999.000 & 0.575 \\
\hline & 2 & 0.931 & 0.110 & $*$ & 0.497 \\
\hline & 3 & 1.168 & 0.113 & $*$ & 0.620 \\
\hline & 4 & 1.295 & 0.129 & $*$ & 0.655 \\
\hline & 5 & $0.88 I$ & 0.108 & $*$ & 0.470 \\
\hline
\end{tabular}

Note: $* P<0.001$.

or more complications (ie, hypertension, diabetes, and hyperlipidemia) would have better knowledge related to CAD. ${ }^{20,55}$ Comparing with those living in the rural areas, the patients living in the cities have access to better health care resources and public health insurance, which help them acquire CAD-related knowledge more easier. ${ }^{55}$ Consistent with the previous study, patients who have two or three complications showed better CAD-related knowledge than those without complication. ${ }^{20}$ The possible reason was that these complications were also the risk factors of CAD.

\section{Limitations}

This study had some limitations. First, the convenient sampling limited the representativeness of the target population with $\mathrm{CAD}$, which might restrict the generalization of the findings. Second, the participants in this study were recruited from a single city in China. Future studies needed to be conducted throughout different geographic locations in China. Considering the four-factor model of the questionnaire was established by the original author via EFA, this study only tested the hypothetical model through CFA, and EFA was not conducted. Further study could perform EFA to explore the internal factorial structure of the Chinese version of the CADEQ-II and compared with this four-factor structure. Finally, the test-retest reliability and convergent validity were not evaluated in this study, which needed to be considered in future studies.

\section{Conclusion}

This study translated and validated the Chinese version of CADEQ-II in Chinese patients hospitalized with CAD. The results confirmed that the Chinese version of CADEQ-II was a valid tool to measure the disease-related knowledge among Chinese patients hospitalized with CAD. It also provided an appropriate reference for developing individualized education plan related to CAD and an accurate measurement for evaluating the effectiveness of the education program in future research.

\section{Acknowledgments}

The authors would like to thank all the participants. We are grateful for the permission from Dr Gabriela Lima de Melo Ghisi for using the instrument and her kind help. 


\section{Disclosure}

The authors report no conflicts of interest in this work.

\section{References}

1. Fuster V. Global burden of cardiovascular disease: time to implement feasible strategies and to monitor results. $J$ Am Coll Cardiol. 2014; 64(5):520-522.

2. WHO. WHO Global InfoBase; 2011. Available from: https://apps.who. int/infobase/CountryProfiles.aspx. Accessed August 7, 2018.

3. West RR, Jones DA, Henderson AH. Rehabilitation after myocardial infarction trial (RAMIT). Heart. 2013;99(2):146.

4. Hu S, Gao R, Liu L, Zhu M. Report on Cardiovascular Disease in China 2015. Beijing: Encyclopedia of China Publishing House. 2015.

5. Ghisi GL de M, Abdallah F, Grace SL, Thomas S, Oh P. A systematic review of patient education in cardiac patients: do they increase knowledge and promote health behavior change? Patient Educ Couns. 2014;95(2):160-174.

6. Heran BS, Chen JM, Ebrahim S, et al. Exercise-based cardiac rehabilitation for coronary heart disease. In: Taylor RS, editor. Cochrane Database of Systematic Reviews. Chichester: John Wiley \& Sons, Ltd; 2011:CD001800.

7. Bergman HE, Reeve BB, Moser RP, Scholl S, Klein WM. Development of a Comprehensive Heart Disease Knowledge Questionnaire. Am J Health Educ. 2011;42(2):74-87.

8. Yan YX, Dong J, Liu YQ, et al. Association of suboptimal health status and cardiovascular risk factors in urban Chinese workers. $J$ Urban Health. 2012;89(2):329-338.

9. Weibel L, Massarotto P, Hediger H, Mahrer-Imhof R. Early education and counselling of patients with acute coronary syndrome. A pilot study for a randomized controlled trial. Eur J Cardiovasc Nurs. 2016; 15(4):213-222.

10. Goossens E, Fieuws S, van Deyk K, et al. Effectiveness of structured education on knowledge and health behaviors in patients with congenital heart disease. J Pediatr. 2015;166(6):1370-1376.

11. Boyde M, Turner C, Thompson DR, Stewart S. Educational interventions for patients with heart failure: a systematic review of randomized controlled trials. J Cardiovasc Nurs. 2011;26(4):E27-E35.

12. Anderson L, Brown JP, Clark AM, et al. Patient education in the management of coronary heart disease. Cochrane Database Syst Rev. 2017;6:CD008895.

13. de Melo Ghisi GL, Grace SL, Thomas S, Evans MF, Sawula H, Oh P. Healthcare providers' awareness of the information needs of their cardiac rehabilitation patients throughout the program continuum. Patient Educ Couns. 2014;95(1):143-150.

14. Ghisi GL, Durieux A, Manfroi WC, et al. Construction and validation of the CADE-Q for patient education in cardiac rehabilitation programs. Arq Bras Cardiol. 2010;94(6):813-822.

15. Shaolin S, Ming D, Jianhua Z. Review of the experimental studies about the coronary artery disease education by nurses in China. J Nurses Train. 2010;25(9):793-795.

16. Qian X, Qinghua Z, Yihau T, Mingchao X. Evaluation of the effects of the patient education about coronary artery disease: a qualitative study. J Nurse Train. 2014;29(3):216-218.

17. Meilian X, Tao X. Survey on disease related knowledge in inpatients with coronary heart disease and its influencing factors. J Nurs Sci. 2008;23(17):19-20.

18. Meihua D, Jin H, Sha S. Correlations between knowledge and compliance of home-based patients with coronary artery disease. Nursing $J$ Chinese People's Liberation Army. 2013;11:19-21.

19. Xiao M. Evaluation of effectiveness of education intervention on inpatients with coronary heart disease [master's thesis]. Changsha: Central South University; 2007.

20. Ghisi GL, Grace SL, Thomas S, Evans MF, Oh P. Development and psychometric validation of the second version of the Coronary Artery Disease Education Questionnaire (CADE-Q II). Patient Edu Couns. 2015;98(3):378-383.
21. Ghisi GL de M, Oh P, Thomas S, Benetti M. Assessment of patient knowledge of cardiac rehabilitation: Brazil vs Canada. Arq Bras Cardiol. 2013;101(3):255-262.

22. de Melo Ghisi GL, Oh P, Thomas S, Benetti M. Development and validation of an English version of the Coronary Artery Disease Education Questionnaire (CADE-Q). Eur J Prev Cardiol. 2013;20(2):291-300.

23. de Melo Ghisi GL. Development of an educational curriculum for cardiac rehabilitation patients and their families. J Clin Exp Cardiolog. 2015;6(5).

24. Skinner CS, Campbell MK, Rimer BK, Curry S, Prochaska JO. How effective is tailored print communication? Ann Behav Med. 1999; 21(4):290-298.

25. Languages/Translations. CADE-Q Studies. Available from: https:// cadeq.wordpress.com/languagestranslations/. Accessed July 24, 2018.

26. Guillemin F, Bombardier C, Beaton D. Cross-cultural adaptation of health-related quality of life measures: literature review and proposed guidelines. J Clin Epidemiol. 1993;46(12):1417-1432.

27. Beaton DE, Bombardier C, Guillemin F, Ferraz MB. Guidelines for the process of cross-cultural adaptation of self-report measures. Spine. 2000;25(24):3186-3191.

28. Rajalahti T, Kvalheim OM. Multivariate data analysis in pharmaceutics: a tutorial review. Int J Pharm. 2011;417(1-2):280-290.

29. Steel RGD, Torrie JH. Principles and Procedures of Statistics: A Biometrical Approach. 3rd ed. New York: McGraw-Hill; 1997.

30. Lynn MR. Determination and quantification of content validity. Nurs Res. 1986;35(6):382:386-386.

31. Mastaglia B, Toye C, Kristjanson LJ. Ensuring content validity in instrument development: challenges and innovative approaches. Contemp Nurse. 2003;14(3):281-291. http://www.ncbi.nlm.nih.gov/ pubmed/12868667

32. Grant JS, Davis LL. Selection and use of content experts for instrument development. Res Nurs Health. 1997;20(3):269-274.

33. DMcg R, Berg-Weger M, Tebb SS, Lee ES, Rauch S. Objectifying content validity: conducting a content validity study in social work research. Social work research. Soc Work Res. 2003;27(2):94-104. Available from: http://xueshu.baidu.com/s?wd=paperuri\%3A\%28e8c debe3b29570d8abfe00d9af490152\%29\&filter=sc_long_sign\&sc_ks_ para $=q \% 3$ DObjectifying content validity $\% 3$ A Conducting a content validity study in social work research\&sc_us=11519133154796473676. Accessed September 24, 2017.

34. Sim SM, Rasiah RI. Relationship between item difficulty and discrimination indices in true/false-type multiple choice questions of a para-clinical multidisciplinary paper. Ann Acad Med Singapore. 2006; 35(2):67-71.

35. Parmenter K, Wardle J. Development of a general nutrition knowledge questionnaire for adults. Eur J Clin Nutr. 1999;53(4):298-308.

36. Ebel RL. Procedures for the analysis of classroom tests. Educ Psychol Meas. 1954;14(2):352-364.

37. Nunnally JC. Psychometric Theory. New York: McGraw-Hill; 1978. Available from: http://search.ebscohost.com/login.aspx?direct=true $\& \mathrm{db}=$ edshtl $\& A N=$ mdp.39015020710326\&site=eds-live. Accessed June 7, 2018.

38. Gazmararian JA, Williams MV, Peel J, Baker DW. Health literacy and knowledge of chronic disease. Patient Educ Couns. 2003;51(3): 267-275.

39. Khan MS, Jafary FH, Jafar TH, et al. Knowledge of modifiable risk factors of heart disease among patients with acute myocardial infarction in Karachi, Pakistan: a cross sectional study. BMC Cardiovasc Disord. 2006;6(1):18.

40. Potvin L, Richard L, Edwards AC. Knowledge of cardiovascular disease risk factors among the Canadian population: relationships with indicators of socioeconomic status. CMAJ. 2000;162(9 Suppl):S5-S11.

41. Jacob KS, Everitt BS, Patel V, Weich S, Araya R, Lewis GH. The comparison of latent variable models of non-psychotic psychiatric morbidity in four culturally diverse populations. Psychol Med. 1998; 28(1):145-152. 
42. Yuan K-H, Bentler PM. 5. Three Likelihood-Based Methods for mean and covariance structure analysis with nonnormal missing data. Sociol Methodol. 2000;30(1):165-200.

43. Brown T. Confirmatory Factor Analysis for Applied Research. New York: The Guilford Press; 2006.

44. Steiger JH, Evaluation SM. and Modification: an interval estimation approach. Multivariate Behav Res. 1990;25(2):173-180.

45. Barrett P. Structural equation modelling: adjudging model fit. Pers Individ Dif. 2007;42(5):815-824.

46. Pett MA, Lackey NR, Sullivan JJ. Making Sense of Factor Analysis: The Use of Factor Analysis for Instrument Development in Health Care Research. California: Thousand Oaks; 2003. Available from: http:// search.ebscohost.com/login.aspx?direct $=$ true $\& \mathrm{db}=$ edsnuk $\& \mathrm{AN}=\mathrm{edsn}$ uk.vtls000445336\&site=eds-live. Accessed June 7, 2018.

47. Brennan RL. Generalizability theory and classical test theory. Appl Meas Edu. 2010;24(1):1-21.

48. Qian X. Research on the outcome of assessment index system for health education of coronary diseases [master's thesis]. Chongqing: Chongqing Medical University; 2015.

49. Ling X, Qinghua Z, Minghua X. The progress of health education model of coronary heart disease. Chinese J Pract Nurs. 2016;32(8):637-640. http://d.g.wanfangdata.com.cn/Periodical_syhlzz201608019.aspx
50. Hair JF, Anderson RE, Tatham RL, Black WC. Multivariate Data Analysis. 5th ed. New Jersey: Hall Prentice; 1998.

51. Kopp LR. Knowledge and attitudes towards cardiovascular disease in a population of North Western Turkey: a cross-sectional survey. Int $J$ Caring Sci. 2015;8(1):115-124.

52. Kayaniyil S, Ardern CI, Winstanley J, et al. Degree and correlates of cardiac knowledge and awareness among cardiac inpatients. Patient Educ Couns. 2009;75(1):99-107.

53. Zhou Y, Li J, du S, et al. Cardiac rehabilitation knowledge in patients with coronary heart disease in Baoding city of China: a cross-sectional study. Int J Nurs Sci. 2017;4(1):24-28.

54. Duber HC, Mcnellan CR, Wollum A, et al. Public knowledge of cardiovascular disease and response to acute cardiac events in three cities in China and India. Heart. 2018;104(1):67-72.

55. Jing $\mathrm{Z}, \mathrm{Bi} \mathrm{T}$, Jian $\mathrm{Z}$, et al. Investigation and influencing factors of the disease related knowledge in hospitalized patients with coronary heart disease. J Qiqihaer Univ Med. 2016;37(22): $2837-2840$.

\section{Publish your work in this journal}

Patient Preference and Adherence is an international, peer-reviewed, open access journal that focuses on the growing importance of patient preference and adherence throughout the therapeutic continuum. Patient satisfaction, acceptability, quality of life, compliance, persistence and their role in developing new therapeutic modalities and compounds to optimize clinical outcomes for existing disease states are major areas of interest for the journal. This journal has been accepted for indexing on PubMed Central. The manuscript management system is completely online and includes a very quick and fair peer-review system, which is all easy to use. Visit http://www dovepress.com/testimonials.php to read real quotes from published authors. 